\title{
DCNN-GCM: A Deep CNN and Granger Causality Models for Forecasting Welfare Level of Energy-Producing Countries and Evaluating the Relationship between Energy Consumption and Sustainable Economic Welfare
}

\author{
Nasser Hoseinbor $\mathbb{D}^{\mathbb{D}},{ }^{1}$ Seyed Nematollah Mousavi $\mathbb{D}^{\mathbb{D}},{ }^{2}$ and Abbas Aminifard ${ }^{3}$ \\ ${ }^{1}$ Department of Oil and Gaz Economics, Islamic Azad University, Marvdasht Branch, Shiraz, Iran \\ ${ }^{2}$ Department of Agricultural Economics, Islamic Azad University, Marvdasht Branch, Shiraz, Iran \\ ${ }^{3}$ Department of Economics, Islamic Azad University, Shiraz Branch, Shiraz, Iran \\ Correspondence should be addressed to Seyed Nematollah Mousavi; snmousavi@miau.ac.ir
}

Received 24 October 2021; Revised 3 December 2021; Accepted 9 December 2021; Published 21 January 2022

Academic Editor: Saeid Jafarzadeh Ghoushchi

\begin{abstract}
Copyright (c) 2022 Nasser Hoseinbor et al. This is an open access article distributed under the Creative Commons Attribution License, which permits unrestricted use, distribution, and reproduction in any medium, provided the original work is properly cited.
\end{abstract}

\begin{abstract}
From the beginning of creation, human beings have realized the importance of energy for survival. They have always devoted a significant part of their energy to provide the required energy. Moreover, it can be said that energy resources have an essential role in the life and evolvement of societies. On the contrary, with the depletion of energy resources, severe environmental pollution caused by the consumption of petroleum products, and high cost of energy in the production cycle, allocating these resources must be carried out carefully. This paper aims to look at the connection between energy consumption and sustainable economic welfare in OPEC countries (Iran, Kuwait, Saudi Arabia, UAE, Ecuador, and Venezuela) during 2019-2009, utilizing the panel data method. Finally, we presented a CNN architecture for forecasting welfare levels in the case study countries. As a result, the relationship between energy consumption and economic growth among selected countries from energy-producing countries was compared in this analysis, which used the standard Granger causality test and the Granger causality test in several domains. The findings suggest that economic growth and inflation positively impact energy consumption in the countries studied. In addition, energy consumption positively impacts these countries' sustainable economic welfare, while inflation has a negative effect. In addition, the findings of the standard Granger causality test indicate a one-way causal association between energy consumption and economic development in Iran and Venezuela, as well as one-way causality from GDP to energy consumption in Ecuador, the United Arab Emirates, Saudi Arabia, and Kuwait. Also, based on the results of the CNN method, the RMSE are 1.75, 3.81, 1.39, 0.52, 0.69, and 1.72 for Ecuador, Emirates, Iran, Saudi Arabia, Kuwait, and Venezuela, respectively.
\end{abstract}

\section{Introduction}

Assessing sustainability and welfare is a contemporary issue of scientific and political importance. The Sustainable Development Goals of the United Nations aim to achieve a global transition to a world where all citizens experience high human well-being while not expanding the Earth's borders. More scientists argued as civilization developed that economic growth is the best way to accomplish the aims of sustainable development, with human welfare at its heart. Human well-being is a fundamental idea in humannature interaction. The general population has largely agreed on the value of human well-being, influenced by social, environmental, and personal influences. Economic sustainability and energy use are essential considerations in achieving long-term social and economic development. Economic growth is often followed by energy consumption, which leads to socio-economic development and creates several environmental issues that offset the increase in human well-being. Using energy significantly improves 
human well-being. Sustainable development has made energy, the environment, and the economy an essential issue for academia and global governments. Human wellbeing is a complicated, contentious, and ever-changing term. Economic, health, cultural, and social security are aspects of human well-being in the broadest sense. According to Wang et al. [1], human well-being serves as a connection between the natural world and human society. On the contrary, energy plays a critical role in human life and economic operations, serving as an indicator of wellbeing, economic and social progress, and a vital humanitarian need. As a result, per capita, energy consumption is an essential measure of a country's growth and economic progress. In the current time, energy is seen as a raw material for manufacturing and a strategic asset that shapes international affairs, the global economy, and politics. Energy supply conditions and challenges encountered during the procurement process significantly impact national and international competition. These factors also form country demand systems and are among the most important indices of essential economic variables. For all of these causes, electricity is one of the world's most pressing concerns today. Due to the importance of the subject, in the continuation of the work, we present the theoretical foundations and review the research background to introduce the model and related tests.

The expansion of a country's wealth allows it to continue to improve the well-being of its people. Some of the advantages of urban growth include improved nutrition, healthy lifestyle, increased life expectancy, increased adult literacy, lower child mortality rate, increased mobility, and increased recreation and leisure facilities. On the contrary, present economic growth should not result in higher environmental expenses since future development is dependent on it. While economic consumption by humans is called welfare, Max Neef [2] notes a threshold hypothesis in his research on economic growth and life quality. However, based on this person's desires and between increased consumption and increased wealth, a limit to economic development is reached. From this point on, certain luxury products' social and environmental costs tend to reverse human happiness. To put it in another way, environmental sustainability must be promoted to achieve stability. Since 1969, international organizations have released the Pearson Report, an overview of global growth that questions these development consequences and examines several causes, emphasizing that the long-term advantage of all economies, regardless of scale, is to make the most of human and material resources [3]. Around the same time, it expands the agriculture market and meets a broader range of people. Natural resources have the resources and environmental services that we depend on for our well-being, so green growth is the driving force behind sustainable growth and sustainability [4]. As a result, investment and creativity must be examined, as they would be the foundation for long-term development and the creation of new economic opportunities [5]. Some scholars, such as Miller [6], have concluded that human naivety and technological advancements make it easier to lessen the environmental harm generated by economic development. Seeking alternatives to finite resources and growing the Earth's capacity to sustain humanity are both reasonable options. As a result, achieving societal welfare is one of the most critical priorities of an economy [7]. However, there is disagreement about the various factors that affect these conditions. Indexes should be classified according to regional patterns. They should consider and enhance current data, covering all social, economic, environmental, and structural aspects [8] and [9]. Li et al. [10] have studied the effect of social and natural environmental elements on building energy. In another research, Qian et al. [11] have concluded a renewable energy accounting as an indicator of observation. JafarzadehGhoushchi et al. [12] have studied on seasonal storage solar energy system stage in Iran using a statistical model. According to Nodhaus and Tobin [13], the usual international standard of economic development lacks the essential elements of socio-economic security, natural resource utilization, and environmental quality. They developed a new method of calculating welfare that included per capita consumption (in which economic assets were increased and expenses were reclassified), recreation, and other nonmarket modes of activity, as well as deducting urbanization costs [14]. Most developed countries have made changes in health and education that have lasted almost two decades in advanced countries. However, GDP continues to be used to gauge welfare $[15,16]$. The ISEW index was established by Costanza in 1990 and updated in 1993 to assess the long-term viability of people's perceived welfare standards. Economic, distributive, societal, and environmental variables are included. Guimaraes et al. [8], reflect on societal economics from the viewpoint of a capitalist economy that adheres to neoclassical theory and liberalism in practice. An alternative methodology to assessing economic development depending on real-world requirements proposes the development of the Index Sustainable Economic Welfare (ISEW), which includes variables such as income distribution, net capital growth, foreign and domestic capital, natural resource depletion, environmental damage, and the value of unpaid domestic work [14] and [17]. We have used the Granger causality model to compare the causality relationship between energy use and economic development in various realms in OPEC member countries, including Iran and Ecuador, the United Arab Emirates, Saudi Arabia, Kuwait, and Venezuela. In this study, with identifying the relationship between energy consumption and sustainable economic welfare in these nations, we will evaluate and compare the relationship between energy consumption and economic development in Iran and other countries. A CNN model was also presented for forecasting welfare levels in the research report countries.

\section{Literature Review}

In their report, Sánchez et al. [14] used data from Ecuador from 2001 to 2015 to quantify the ISEW. They also contrasted the ISEW to GDP as development indicators, emphasizing the distinction between stability and economic growth. The findings suggest that personal consumption is one of the most beneficial and essential components in 
increasing long-term welfare. The destruction of natural resources negatively affects the welfare of Ecuador. The gap between sustainable welfare and GDP has been confirmed. In their study, Azami and Almasi [18] look at the connection between energy consumption and sustainable economic welfare in oil-producing countries. They look at the ISEW first and then connect energy consumption and sustainable economic welfare in these countries [19]. Personal consumption and energy reduction are considered components of sustainable welfare. The findings, calculated using Westerlund [20] test and taking cross-sectional dependency into account, show that energy use and Sustainable Economic Welfare have a long relation. The Granger causality test reveals a one-way relationship between sustainable economic welfare and energy use. This result has implications for energy and environmental policymakers. Wang et al. [21] used the PSR approach and factor weight ranking method to assess ecologically responsible development. Olubiyi [22] uses the Generalized System Torque (SYSGMM) approach to analyze the link between energy consumption, carbon dioxide emissions, and welfare. The findings reveal a one-way causal relationship between coal use and per capita revenue. There was also evidence of oneway causality between death and coal use and carbon dioxide emissions. Furthermore, there is a two-way association between death and energy consumption. The findings of the SYS-GMM demonstrate that energy consumption has a wide range of consequences on welfare. Enhancement coal consumption lowers unemployment while raising energy consumption lowers infant mortality. The use of fossil fuels hastens death. Carbon dioxide emissions lower unemployment, but they boost child mortality rates. Infant mortality is often reduced as a result of increased energy intake. In their report, Roach and Meeus [23] look at the effect of energy policies on societal welfare. Energy strategies are mixed with the problem of product development management to meet their targets, resulting in a detailed model for development strategy from the perspective of a manufacturing organization. This method is applied in GAMS optimization applications using the BARON optimizer as a nonlinear mixed-integer (MINLP) solution. In addition, two alternative scenarios without the quota commitment strategy and its associated costs have been discussed to address the issue. The virtual price index is used to measure social security (VPI). The findings show that the subscriber welfare surplus increases in the long run, but it is lower than the short-term average. Furthermore, the introduction of the quota contribution scheme of tradable green certificates raised the penetration of clean energy sources (more than $60 \%$ ) and the excess welfare (more than \$107). In the second example, the cost of production falls as the number of cleaning services grows. Ahmadi et al. [24] have studied a new expert system model using programming in the industry [24].

In their research, Phoumin and Kimura [25] looked at the impact of energy shortages on household welfare in Cambodia. Household energy insecurity is described in this study as the current situation caused by inadequate energy intervention, which prevents the supply of specific household energy needs. Since energy insecurity differs from location to place, it can only be fully understood by local studies. Households with insufficient energy intake could be missing out on a plethora of other resources. The results show that energy poverty has a significant negative effect on household health, with an even greater impact on children's human capital development. There are many studies that have used artificial intelligence methods for predicting such as local wavelet and MLP methods for classification underwater targets [26] and wavelet convert for forecasting short-term PM10 condensation [27]. Blonz [28] identifies and determines the costs associated with an energy-efficient alternative to home appliances in his research. He points out that agents hired by the company are increasing their losses by misreporting to allow unauthorized refrigerators to be replaced deliberately. He also provides empirical estimates of the effects of these incentives on (1) the effectiveness of energy resilience and (2) welfare. Unqualified shifts are found to reduce welfare by an average of $\$ 106$. Only half of the employees who follow the instructions save, increasing welfare by $\$ 60$ per replacement. Sharifi et al. [29] have studied the influence of artificial intelligence and digital style on industry and energy during the pandemic. Ahmadi [30] has used computational modeling using GEP and logarithmic fuzzy preference programming to prioritize the economic growth factors. Also, in another research, Ghorbani et al. [31] have analyzed a statistical investment plan for call and put option pricing. Boughanmi et al. [32], in their research, evaluate the overall economic effects of rising energy prices in Oman through income distribution indices reflected in Gini coefficients and other inequality indices. The results show that the effects of a $50 \%$ reduction in energy subsidies will lead to a $0.62 \%$ increase in GDP, an increase in government savings of $\$ 2.9$ billion, and a 3\% decrease in household welfare. The main reason is the increase in the private consumer price index. However, the effect on the Gini coefficient is negligible. In the short run, income inequality is less sensitive to subsidy reform. In another study, Ghorbani et al. [33] have calculated an option pricing using investment plan with the haphazard interest price. In their study, Peng et al. [34] found that, while China's energy intensity has steadily decreased in recent years, the overall consumption of energy products has risen exponentially. One of the keys to managing energy demand is indirect energy taxes. In order to simulate indirect taxation in Jiangsu Province, one of China's most critical economic provinces with limited energy supplies, they established a computable general equilibrium model. The findings suggest that indirect taxes reduce energy consumption while direct energy taxes reduce economic and social welfare. When tax thresholds are $5 \%, 10 \%$, and $15 \%$, the GDP loss is 0.27 percent, 0.66 percent, and 1.13 percent. Qiao et al. [35] have used a wavelet transform for forecasting the disparity among natural gas producers and consumers in the United States on a monthly basis. Qiao et al. [36] have analyzed forecasting of US electricity production regarding a hybrid new model using artificial intelligence. Peng et al. [37] have investigated the impact of a blocked rectifier on metering efficiency in shale fossil fuel extraction. Peng et al. [38] have studied monthly oil and gas load forecasting using a wavelet cutoff 
noise removal method and a mix of long-short-term memory. In the study of Agaa et al. [39], PV output power was predicted using CNN-LSTM and ConvLSTM models. The results demonstrate that the proposed strategies outperform a standard LSTM model in terms of accuracy. Sharifi et al. [40] have studied a novel model based on gene expression programming for predicting NOx emissions in engine diesel. Ahmadi et al. [41] have studied and designed a novel hybrid method for predicting GDP factors using artificial intelligence and statistical methods. The results show that the models forecast the factors with high accuracy. In the study of Khan et al. [42], a novel multistep forecasting model was suggested for power consumption. The proposed approach attains better predictive performance than existing methods, thereby confirming its effectiveness. Ahmadi and Taghizadeh [43] presented a GEP model for economy growth indicators using ARDL and PCA testing methods. The findings show that the models are applied for the assessment of the GDP and knowledge-based economy. Ghorbani and Korzeniowski [44] have analyzed an adaptive risk hedging for under Cox-Ingersoll-Ross bond yields. Also, in another research, Korzeniowski and Ghorbani [45] have analyzed a model investment for Hull-White bond yields. Taghizadech and Ahmadi [46] have studied a statistical analysis using Tukey and ARDL bound methods for assessment of knowledge-based economy factors on GDP in Iran. The findings suggest that statistical methods can evaluate the significance of the factors. Farsi et al. [47] used a novel method dubbed parallel LSTM-CNN on short-term load prediction. The findings suggest that deep CNN models, particularly PLCNet, are strong candidates for short-term prediction.

\section{Methods and Materials}

3.1. Theories of Sustainable Economic Welfare. Sustainable economic welfare has been related to an individual's degree of satisfaction by some authors, including Marshall [48],
Hicks [49], and Pigou [50]. Economic welfare, in their opinion, refers to how satisfied people are in their purchases of goods and services. However, it is not all about material goods because "economic welfare and social welfare are intrinsically linked." This view is supported by recent studies such as Deaton [51] which claim that welfare is measured in ways other than income. It is interesting to note that "wellbeing" does not imply "consumption" or "economic prosperity," but rather "quality of life" [52]. Furthermore, influences affecting well-being include wages, income distribution, working environments, people's leisure time, production, and the environment [53-56]. Sen [57], for example, introduces a new definition of well-being that stresses the distinction between "being in a healthy situation" and "getting well-being." The desire to keep away from alien artifacts and luxury was among the first. In this case, welfare is linked to inner wishes that can be fulfilled with effort. He also agrees that social and economic conditions affect various classes of people and influence their choice of opportunities. The number of people living below the poverty line is a standard metric for measuring a country's welfare. However, it lacks the differing degrees of poverty among the poor. For this purpose, Sen [57] considers the well-being of individuals to measure the poverty index [14].

3.2. Dataset and Problem Formulation. The method of integrating time-series and cross-sectional data was used to examine the connection between GDP and energy usage, the general level of costs, etc., for the period 2009-2019. Also, the effect of the logarithm of GDP variables and the general level of prices in the countries is studied, and the logarithm of energy use and also the effect of the logarithm of energy consumption variables and the general level of prices on the logarithm of GDP using effect models, common, fixed effects, and random effects are analyzed. The data panel approach is used to analyze the association between economic welfare and energy consumption:

$$
\begin{aligned}
\operatorname{LOG}\left(E_{\mathrm{it}}\right) & =\beta .+\beta_{1} \operatorname{LOG}\left(\mathrm{GDP}_{t}\right)+\beta_{2} \operatorname{LOG}\left(P_{t}\right)+\beta_{3} \operatorname{LOG}\left(\mathrm{GDP}_{t-1}\right)+\beta_{4} \operatorname{LOG}\left(E_{t-1}\right)+\varepsilon_{\mathrm{it}}, \\
\operatorname{LOG}\left(\mathrm{GDP}_{\mathrm{it}}\right) & =\beta .+\beta_{1} \operatorname{LOG}\left(P_{\mathrm{it}}\right)+\beta_{2} \operatorname{LOG}\left(\mathrm{GDP}_{\mathrm{it}-1}\right)+\beta_{3} \operatorname{LOG}\left(E_{\mathrm{it}}\right)+\varepsilon_{\mathrm{it}} .
\end{aligned}
$$

In this regard, GDP represents economic welfare, which uses GDP as a measure of welfare. $\mathrm{P}$ also indicates the general level of prices, and $\varepsilon$ is also a disturbance.

3.3. Convolutional Neural Network (CNN). $\mathrm{CNN}$ is a type of feedforward neural network that excels at computer vision and natural language understanding. It may be used to forecast time series with great success. CNN's local perception and local receptive may substantially limit the number of parameters, boosting model learning efficiency [58] and [59]. The convolution layer and the pooling layer are the two primary components of CNN [60]. Each convolution layer has several convolution kernels, and the method for calculating them is shown in equation (3). The features of the data are retrieved after the convolution operation of the convolution layer. However, the extracted feature sizes are pretty significant. Therefore, a pooling layer is applied after the convolution layer to lower the feature dimension and reduce the cost of training the network:

$$
L_{t}=\operatorname{Tanh}\left(x_{t} k_{t}+b_{t}\right),
$$

where $L_{t}$ is the output of the convolution operator, $x_{t}$ is the input time series, $k_{t}$ is the weight values, and $b_{t}$ is the bias value of the convolutional operator. 


\section{Results}

4.1. Stationarity Analysis Test. In general, we know a random process, and related to it, a time-series stationary. If the variance and its mean are constant over time and the covariance between the two time periods $t$ and $k+t$ depends only on the distance (delay or gap $\mathrm{k}$ ) between the two time periods and not the actual period, $t$ covariance. If one or more of the three stability conditions are not met, we call the random process, or time series, unstable. Based on the test results, most time-series variables are not stationary; instead, they are considered stationary with a definite trend with onetime differentiation. In such cases, the use of unstable time series causes $\mathrm{R} 2, \mathrm{~W}-\mathrm{D}$, and $t$ to lose their standard properties and thus cause problems for the econometric. The use of this data makes the results of regression unreliable and false. Due to this fact, before using the data, it is necessary to perform the necessary tests for the stability of this data by performing the necessary tests. Therefore, we used the generalized Dickey-Fuller test to evaluate the stability of variables, which are presented in the tables. According to Table 1, the hypothesis of a unit root test in the time series for all Ecuadorian variables at the level cannot be rejected. For all variables, it is rejected with a one-time differentiation. In other words, the levels of variables used in the model are unstable, which are stationary once differentiated.

Observing the results of Table 1, it can be concluded that the variables for Ecuador, UAE, Iran, Saudi Arabia, Kuwait, and Venezuela are at a nonstationary level, which is stationary with a one-time differentiation.

4.2. Model Regression Estimation. The results of estimating the above equations are presented in Tables 2 and 3. The fixed-effect model for the studied model was selected as the superior model compared to the expected effects and random effects. The width of different sources can better explain the differences between different countries in this model. The experimental findings of the stable impacts' method show that the logarithm of GDP of this period and the previous period has a beneficial impact on the logarithm of energy usage of the study countries. Therefore, the production capacities of countries are one of the factors affecting the consumption process of primary inputs in general and energy carriers in particular (as secondary inputs). Therefore, changes in production capacity in different sectors of the economy affect the levels of energy demand. Therefore, increasing production in each sector of the economy has overall direct and indirect effects on the energy carrier market. On the contrary, increasing the GDP of countries means increasing the production capacities of these countries. Therefore, increasing GDP in the study group has a positive effect on their energy consumption. Also, the logarithm of energy consumption variables in the previous period and the general level of prices positively affect the logarithm of energy consumption in all countries, with rising prices and the fact that, in the economy of OPEC countries, the energy supply is in the hands of the government, and the
Table 1: Augmented Dickey-Fuller test.

\begin{tabular}{|c|c|c|c|c|c|c|}
\hline Country & Stability & GDPP & OIL & ELEC & GAS & EC \\
\hline \multirow[b]{2}{*}{ Ecuador } & In level & -1.291 & -1.920 & -0.603 & -2.298 & -2.188 \\
\hline & $\begin{array}{c}\text { With } \\
\text { difference }\end{array}$ & -3.428 & -17.185 & -2.158 & -6.009 & -4.521 \\
\hline \multirow[b]{2}{*}{ Emirates } & In level & -1.358 & -2.159 & -0.457 & -2.349 & -2.256 \\
\hline & $\begin{array}{c}\text { With } \\
\text { difference }\end{array}$ & -1.521 & -3.310 & -4.718 & -4.412 & -4.008 \\
\hline \multirow[b]{2}{*}{ Iran } & In level & -1.59 & -2.124 & -3.984 & -4.385 & -4.624 \\
\hline & $\begin{array}{c}\text { With } \\
\text { difference }\end{array}$ & -2.458 & -2.124 & -3.984 & -4.385 & -4.624 \\
\hline \multirow{2}{*}{$\begin{array}{l}\text { Saudi } \\
\text { Arabia }\end{array}$} & In level & -0.048 & -0.978 & -2.551 & -1.682 & -2.151 \\
\hline & $\begin{array}{c}\text { With } \\
\text { difference }\end{array}$ & -3.175 & -3.345 & -6.782 & -5.158 & -4.785 \\
\hline \multirow[b]{2}{*}{ Kuwait } & In level & -0.548 & -1.678 & -2.781 & -1.682 & -2.151 \\
\hline & $\begin{array}{c}\text { With } \\
\text { difference }\end{array}$ & -2.145 & -3.345 & -6.542 & -4.452 & -4.103 \\
\hline \multirow[b]{2}{*}{ Venezuela } & In level & -1.675 & -3.015 & -2.195 & -2.255 & -1.726 \\
\hline & $\begin{array}{c}\text { With } \\
\text { difference }\end{array}$ & -2.572 & -4.478 & -3.951 & -7.112 & -4.123 \\
\hline
\end{tabular}

TABLE 2: Results of estimating the panel data pattern: energy consumption variable.

\begin{tabular}{lccc}
\hline Variables & $\begin{array}{c}\text { Random } \\
\text { effects }\end{array}$ & $\begin{array}{c}\text { Fixed } \\
\text { effects }\end{array}$ & $\begin{array}{c}\text { Fixed } \\
\text { effects }\end{array}$ \\
\hline LGDP & $0.05(0.58)$ & 0.05 & -0.02 \\
LGDP (-1) & $0.19(3.72)$ & $0.09(2.63)$ & $0.05(0.59)$ \\
LP & $0.51(8.98)$ & $0.08(2.82)$ & $0.01(1.87)$ \\
LE (-1) & - & $0.89(23.4)$ & $0.98(55.92)$ \\
$\begin{array}{l}\text { Determination } \\
\text { coefficient }\end{array}$ & 0.99 & 0.92 & 0.90 \\
Durbin-Watson test & 1.71 & 1.90 & 2.25 \\
\hline
\end{tabular}

TABLE 3: Results of estimating the panel data pattern: GDP variable.

\begin{tabular}{lccc}
\hline Variables & $\begin{array}{c}\text { Random } \\
\text { effects }\end{array}$ & $\begin{array}{c}\text { Fixed } \\
\text { effects }\end{array}$ & $\begin{array}{c}\text { Fixed } \\
\text { effects }\end{array}$ \\
\hline LGDP (-1) & $0.86(148)$ & $0.75(12.8)$ & $0.89(158.8)$ \\
LE & $-0.18(-3.98)$ & $0.15(2.61$ & $\begin{array}{c}-0.07 \\
(-0.91)\end{array}$ \\
LP & $-0.004(0.218$ & -0.49 & $\begin{array}{l}-0.05 \\
(-5.2\end{array}$ \\
Determination & 0.99 & 0.92 & 0.90 \\
coefficient & 1.71 & 1.90 & 2.25 \\
Durbin-Watson test & & &
\end{tabular}

government pays energy subsidies for various reasons. It causes the price of energy to increase relatively less than the price of other institutions in the face of inflation, leading to a further increase in energy consumption. Based on F and LM tests' results, the fixed-effect model is selected as the superior method compared to other models. The results of the fixed-effect model indicate that the general level of prices has a negative effect on the GDP of the study countries. In other words, inflation in this group of countries has a negative impact on GDP. This result can be due to the decrease in demand for factors of 
production due to the increase in the price level of inputs, which ultimately leads to a decrease in GDP.

\subsection{Granger Causality between Energy Consumption and} Welfare. According to the stability of the variables, once the differentiation of the VAR model has estimated the difference for each of the selected countries, we performed the standard Granger causality test. The results of the Granger causality test are demonstrated in Table 4. In the Granger linear causality test performed in this section, the two zero hypotheses to be tested are as follows: Granger causality welfare is not energy consumption in selected countries and Granger energy consumption is not economic welfare.

Table 4 illustrates a one-way causal association between economic welfare and energy use in Ecuador, the United Arab Emirates, Saudi Arabia, and Venezuela. There is indeed a one-way relationship between energy use and economic welfare in Kuwait. There is a one-way causal link between energy use and welfare in Iran and Venezuela. Table 5 provides an overview of the findings:

4.4. Granger Causality between Selective Indexes and Economic Growth. Granger causality test between crude oil consumption, natural gas consumption, and electricity consumption with economic welfare was performed using Stata software. Its results are given in Table 6.

The Granger causality test shows one-way causality between crude oil use and economic welfare in Ecuador, the United Arab Emirates, Iran, and Kuwait, as seen in Table 6. There is a one-way causality from electricity consumption to economic welfare in Kuwait and Venezuela and a one-way trigger from economic welfare to electricity consumption in Saudi Arabia. In Ecuador, Iran, and Kuwait, the findings show a one-way causality of economic welfare in natural gas use. There is no causal link between crude oil consumption and economic welfare in Saudi Arabia, between electricity consumption and economic welfare in Ecuador, the UAE, and Iran, and between natural gas consumption and economic welfare in the UAE, Saudi Arabia, and Venezuela. As can be seen from the data, there is no causal relationship between crude oil consumption and economic welfare amongst these selected importing countries. In contrast, there is a one-way causal connection between crude oil consumption and economic welfare among the selected exporting countries, except for Saudi Arabia (see Table 7).

4.5. Granger Causality Test in Many Ranges between Energy Consumption and Welfare. According to Figure 1(a), it can be concluded that there is a causality relationship, in the long run, medium, and short term, from welfare to energy consumption in Iran.

Figure 1(b) shows no causality relationship for Iran in terms of energy consumption to welfare in any of the desired periods. Granger causality was also examined for other countries. However, only results are presented due to limitations. There is indeed a one-way causality connection between energy use and long- and medium-term welfare in Ecuador. In the long run,
TABLE 4: Granger causality results.

\begin{tabular}{lcc}
\hline Country & GDP $\nRightarrow \mathrm{EC}$ & $\mathrm{EC} \nRightarrow \mathrm{GDP}$ \\
\hline Ecuador & 3.378 & 5.215 \\
Emirates & 5.128 & 18.584 \\
Iran & 9.858 & 3.785 \\
Saudi Arabia & 0.758 & 16.850 \\
Kuwait & 0.685 & 8.714 \\
Venezuela & 14.485 & 0.448 \\
\hline
\end{tabular}

TABle 5: Summary of Granger causality results.

\begin{tabular}{ll}
\hline Country & \multicolumn{1}{c}{ Situation } \\
\hline Ecuador & There is a one-way causality from GDPP to EC \\
Emirates & There is a one-way causality from GDPP to EC \\
Iran & There is a one-way causality from EC to GDPP \\
Saudi Arabia & There is a one-way causality from GDPP to EC \\
Kuwait & There is a one-way causality from GDPP to EC \\
Venezuela & There is a one-way causality from EC to GDPP \\
\hline
\end{tabular}

there is a one-way causality relationship between energy use and economic welfare in the UAE. However, in the medium and short term, there is none. In all three long-term, medium-term, and short-term cycles for Iran, there is a one-way causality association between economic welfare and energy use. There is a one-way causality relationship between energy use and economic welfare in Saudi Arabia and Kuwait in the medium term. There is a one-way causality link between economic welfare and long- and short-term energy use in Venezuela.

4.6. Granger Causality Test in Many Ranges between Selected Indexes and Economic Welfare. Figure 2(a) shows that, in the range 0 to 0.08 , there is a Granger causality from the consumption of crude oil to the welfare of Iran. Because this interval includes the interval 0.01 to 0.05 , this interval represents the long-term causality. Therefore, there is a longterm one-way causality of crude oil consumption for the welfare of Iran.

According to Figure 2(b), there is no causality relationship, in the long run, medium, or short term, from welfare to crude oil consumption for Iran. Figure 3 shows the lack of long-term, medium-term, and short-term causality of natural gas consumption to the welfare of Iran.

Figure 4(a) clearly shows the lack of long-term, shortterm, and medium-term causality from the welfare of natural gas consumption for Iran. According to Figure 4(b), in the period of 0 to 0.4 , there is a causality relationship between the consumption of electricity to welfare for Iran. Moreover, since this period includes the long-term range, so it can be said that there is a long-term causality from the consumption of electricity to the welfare of Iran. According to Figures 5(a) and 5(b), it can be concluded that there is no causal relationship in terms of welfare to electricity consumption in Iran in any period. Granger causality was also examined for other countries. However, due to limitations, only results are provided. In Ecuador, there is no causal connection between welfare and electricity consumption 
TABLE 6: Granger causality test results for selected countries.

\begin{tabular}{lcccccc}
\hline Country & OIL $\nRightarrow$ GDPP & GDPP $\nRightarrow$ OIL & ELEC $\nRightarrow$ GDPP & GDPP $\nRightarrow$ ELEC & GAS $\nRightarrow$ GDPP & GDPP $\nRightarrow$ GAS \\
\hline Ecuador & 4.658 & 0.680 & 0.329 & 3.453 & 2.582 & 2.125 \\
Emirates & 15.155 & 2.950 & 3.921 & 0.109 & 2.522 & 8.898 \\
Iran & 35.289 & 0.151 & 1.253 & 15.251 & 0.695 & 0.352 \\
Saudi Arabia & 0.085 & 0.108 & 0.932 & 0.445 & 1.825 & 0.238 \\
Kuwait & 6.868 & 0.0008 & 6.388 & 0.578 & 0.779 & 3.459 \\
Venezuela & 18.815 & 0.387 & 22.712 & & & 3.712 \\
\hline
\end{tabular}

TABLE 7: Summary of Granger causality test results.

\begin{tabular}{llcc}
\hline Country & \multicolumn{1}{c}{ Crude oil consumption } & Electricity consumption & Natural gas consumption \\
\hline \multirow{4}{*}{ Emirates } & One-way causality from OIL to GDPP & There is no causality & One-way causality from GDPP to GAS \\
Oran & One-way causality from OIL to GDPP & There is no causality & There is no causality \\
Saudi Arabia & There is no causality & There is no causality & One-way causality from GDPP to GAS \\
Kuwait & One-way causality from OIL to GDPP & One-way causality from ELEC to GDPP & One-way causality from GDPP to GAS \\
Venezuela & One-way causality from OIL to GDPP & One-way causality from ELEC to GDPP & There is no causality \\
\hline
\end{tabular}

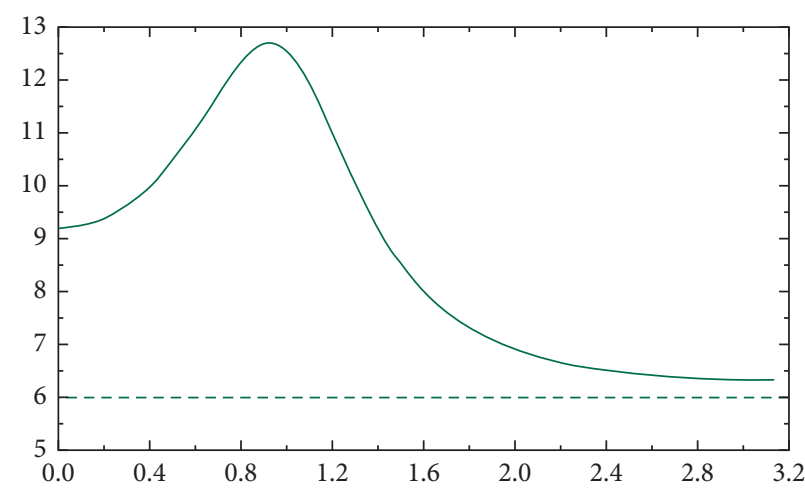

(a)

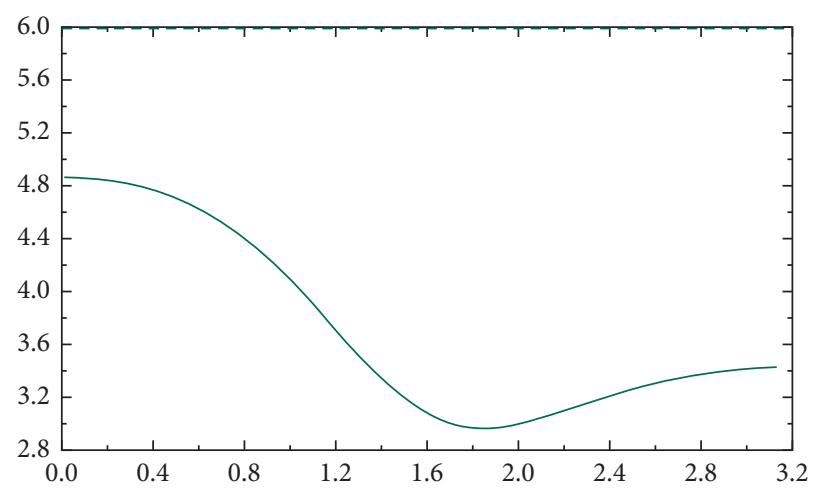

(b)

FIGURE 1: (a) Granger causality in the frequency domain from welfare to energy consumption in Iran. (b) Granger causality in a frequency domain from energy consumption to welfare.

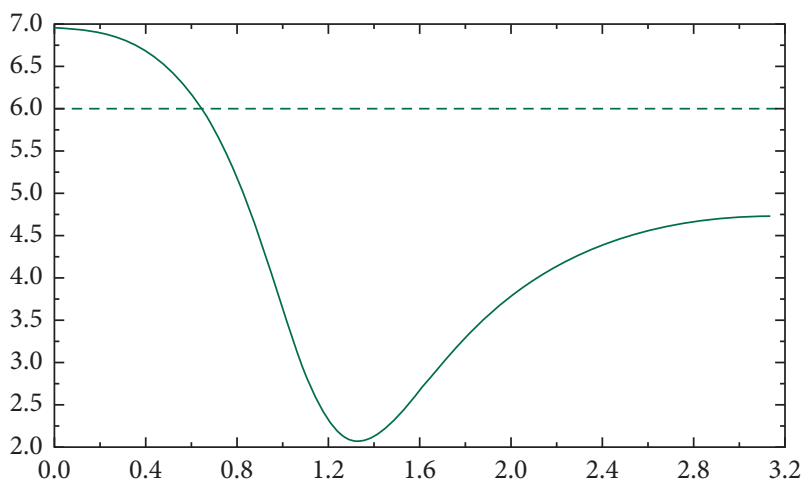

(a)

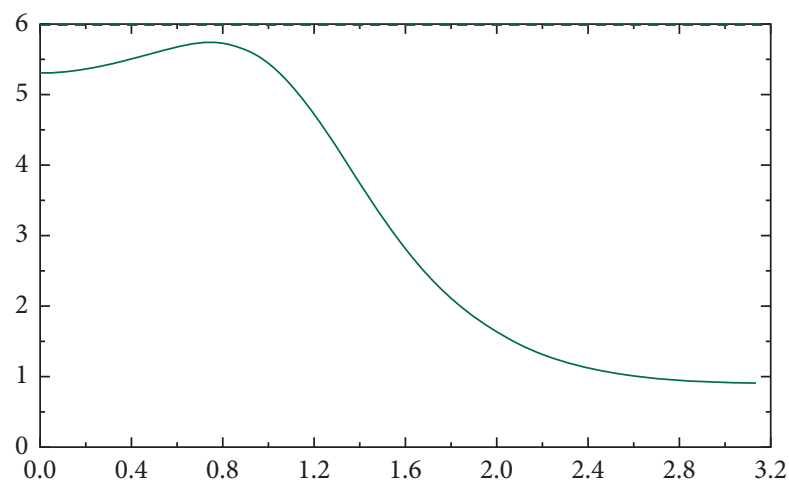

(b)

FIGURE 2: (a) Granger causality in a frequency domain from crude oil consumption to welfare for Iran. (b) Granger causality in a frequency domain of welfare to crude oil consumption for the variable of crude oil consumption in Iran.

and crude oil consumption in all three periods: long term, medium term, and short term, and between welfare and natural gas consumption, there is a one-way causality from welfare to natural gas consumption in the long and medium term. For the UAE, a causality relationship between welfare and electricity consumption and natural gas consumption in 


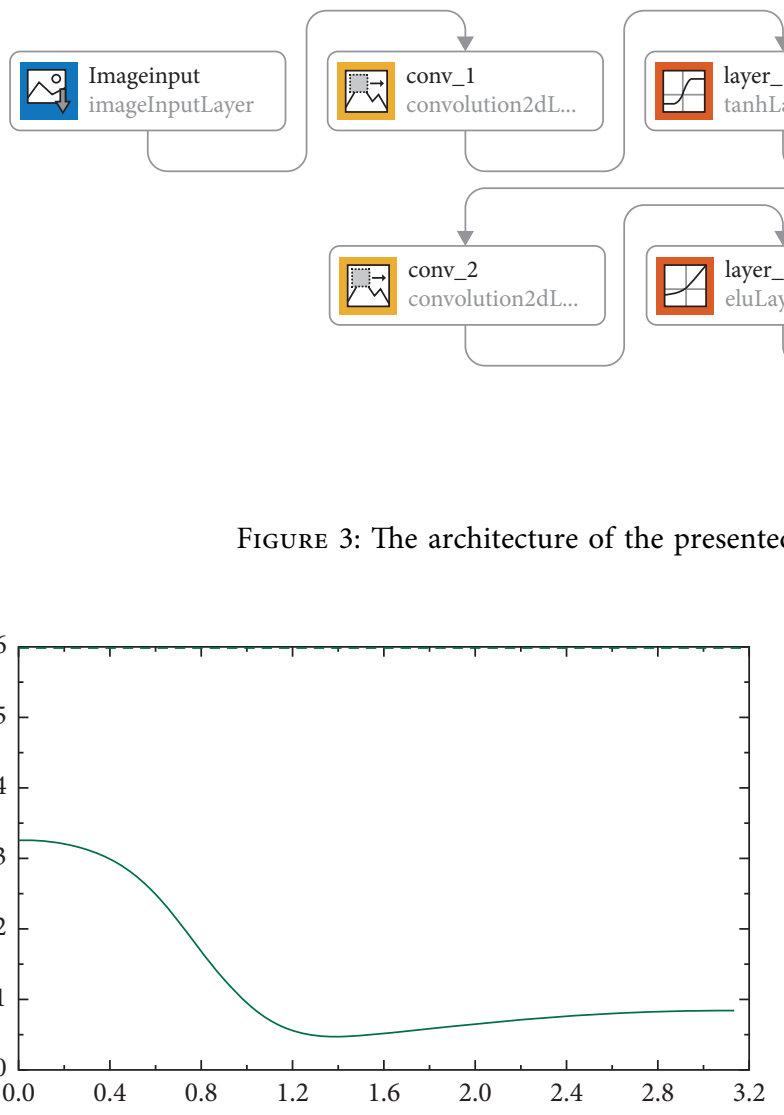

(a)

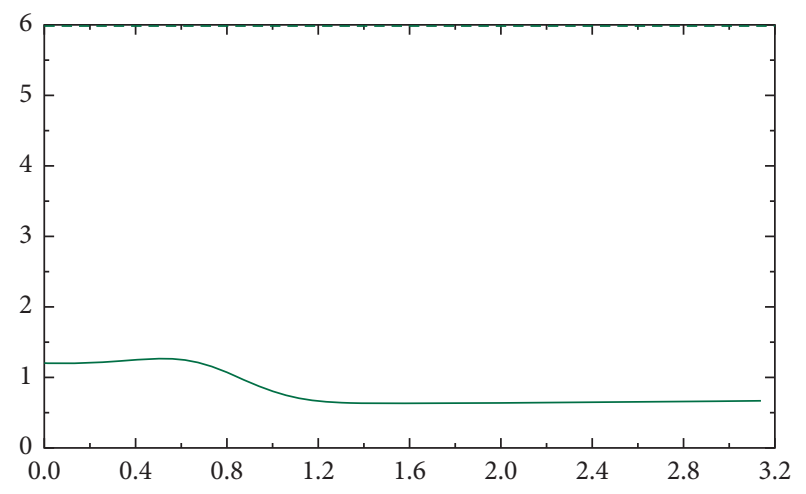

(b)

FIGURE 4: (a) Granger causality in a frequency domain from the consumption of natural gas to welfare for the natural gas variable in Iran. (b) Granger causality in the frequency domain of welfare to natural gas consumption for the natural gas variable in Iran.

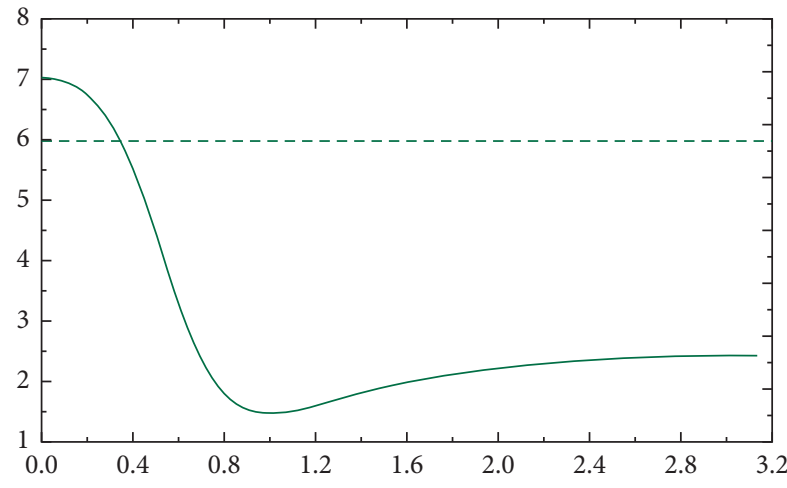

(a)

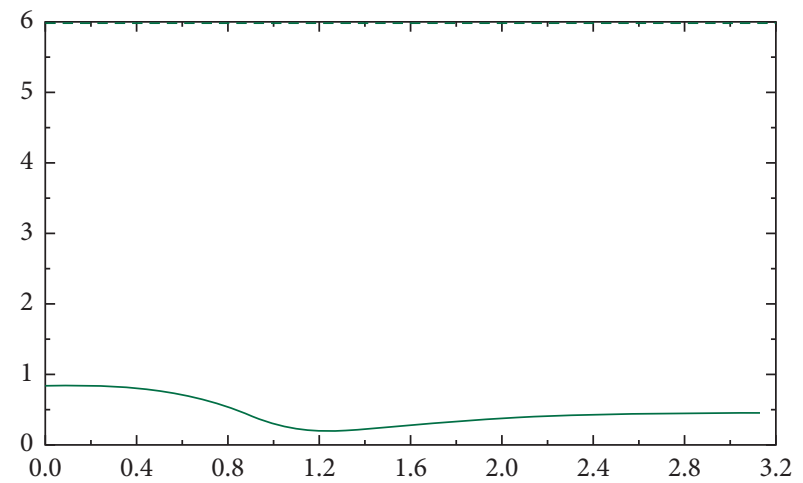

(b)

Figure 5: (a) Granger causality in a frequency domain from the consumption of electricity to welfare for the variable of electricity in Iran. (b) Granger causality in a frequency domain from welfare to electricity consumption in Iran.

all three periods, long-term, medium-term, and short-term, and between welfare and crude oil consumption does not exist; there is a one-way causality from crude oil consumption to welfare only in the long run.

In Iran, there is a long-term one-way causal relationship between welfare and energy use. There is a one-way causality relationship between crude oil consumption and welfare in the long term. There is no causal relationship between natural gas consumption and welfare in any of the three time periods. In the long term, there is a one-way causality link between welfare and natural gas consumption in Saudi Arabia, with natural gas consumption leading to welfare. There is a one-way causal link between welfare and crude oil usage in the long term, with crude oil consumption leading to welfare. In each of the desired cycles, there is no causal link between GDP and electricity usage. There is a one-way 
causality relationship between GDP and natural gas consumption in Kuwait, with natural gas consumption leading to growth in the long run and prosperity leading to natural gas consumption in the medium and short term. There is no causal association between prosperity and energy use or crude oil use in all of the eras. There is a one-way causality relationship between healthcare and energy use in Venezuela at any point in time. There is a one-way causality relationship between welfare and natural gas consumption in the long term, with welfare leading to natural gas consumption. There is a one-way causality relationship from gas output to welfare to crude oil demand in the long and short terms. In the medium term, there is a two-way causality relationship.

4.7. Forecasting Welfare Using Convolutional Neural Network. In this paper, the CNN method is used to forecast the welfare in the countries based on time-series analysis (see Figure 3). The leading network consists of 10 layers of $\mathrm{CNN}$ operators. It includes two convolution operators of analysis (see Table 8).

The architecture and the properties of the layers are presented in Table 8 and Figure 3. The forecasting is evaluated with five lag and two activation functions. The results of forecasting using the $\mathrm{CNN}$ method are illustrated in Figure 6. Based on the training process of Figure 6, the stopping criteria of the model is RMSE that stops the iteration in 250 iterations. Based on the results of the CNN method, the RMSE are 1.75, 3.81, 1.39, 0.52, 0.69, and 1.72 for Ecuador, Emirates, Iran, Saudi Arabia, Kuwait, and Venezuela, respectively. The results of forecasting graphs are depicted with red color in Figure 6. Moreover, the RMSE value is represented in Figure 7.

\section{Discussion and Limitation}

The data imply that, in a few petroleum exporting countries, there is a one-way causation relationship between oil use and economic development. Finally, the results of the two fundamental Granger causality and Granger causality experiments are identical in certain fields. As a result, it is suggested as follows:

(i) Given that energy is one of the main factors in the country's future development and determining and implementing appropriate solutions in all areas related to energy will facilitate sustainable development in the country, despite all the historical events and realities, Iran should try not to consider oil and gas as tools in the political and social spheres. Furthermore, the energy sector as an independent sector to justify the existence of this relationship is expressed in such a way that the share of natural gas consumption in domestic consumption has been very high. Therefore, gas consumption in other parts will not have much impact on welfare.

(ii) Considering oil and gas to achieve other goals in the political sphere only leads to the fact that the conflicts of interest of the spheres will diminish the role of energy resources in itself and as an economic factor. In addition, the principle of using costbenefit analysis should be embedded in all energy sector decisions. Unfortunately, in many cases, the actual costs of projects and their different dimensions are not taken into account. In the final analysis, we conclude that the cost of projects and policies has been much higher than its benefits. Also, reducing energy pollution is central, which should be considered in the future of energy. Finally, it is necessary to have a responsible approach to the exploitation of energy facilities, along with identifying resources, developing a strategy to motivate the emergence of alternative and renewable energy, meeting the capital needs of the energy sector, and dealing fairly with consumers and vulnerable businesses; the efficiency of energy production and consumption management must be planned. In this context, the replacement of fossil fuels is an inevitable prospect. Iran also needs a strategic policy in the energy sector that needs to be formulated and presented by an independent commission of experts, stakeholders, and the High Energy Council. The most crucial point that should be the focus of this policy is a responsible approach to energy use in the country. In short, in the future, the most important oil and gas producers in the world will be Saudi Arabia, Russia, Iraq, and Iran. Moreover, at the same time, due to the ups and downs in the price of energy carriers, the investment approach in this sector is increasing. However, due to the principle of the scarcity of financial resources and political approaches, the use of new investment requires the development of immediate plans for attracting foreign capital. Otherwise, other countries such as Saudi Arabia, Qatar, UAE, Russia, and Kuwait quietly drag the capital market into their borders and use them.

(iii) Medium to high growth of gas consumption in Iran according to the study of gas development indicators in different sectors shows, in recent years, the speed of development of gas subnetworks has been beyond the speed of development of national pipelines, gas refineries, and the upstream part of the gas producer. It shows an unfavorable trend in gas development. The following points are essential about gas production and consumption.

(iv) The country's gas production is growing with the implementation of various projects. Nevertheless, domestic consumption is growing rapidly. Most domestic gas production reaches domestic consumption (domestic, industrial, electricity generation, and injection into oil wells).

(v) Domestic gas consumption fluctuates seasonally, and the possibility of supplying gas to nonhousehold sectors depends directly on the level of household consumption. In the cold winter months, the gas of power plants is cut off, and these units use alternative fuels. 
TABLE 8: The layer properties of the presented CNN method for forecasting time series.

\begin{tabular}{|c|c|c|}
\hline 1 & Input matrix & $5 \times 1 \times 1$ vector with "zerocenter" normalization \\
\hline 2 & Convolution & 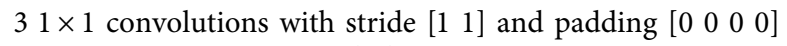 \\
\hline 3 & Tanh & Hyperbolic tangent \\
\hline 4 & Dropout & $50 \%$ dropout \\
\hline 5 & Max pooling & 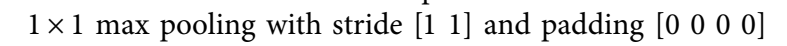 \\
\hline 6 & Convolution & 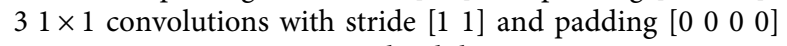 \\
\hline 7 & ELU & ELU with Alpha 1 \\
\hline 8 & Softmax & \\
\hline 9 & Fully connected & One fully connected layer \\
\hline 10 & Regression output & Mean squared error \\
\hline
\end{tabular}
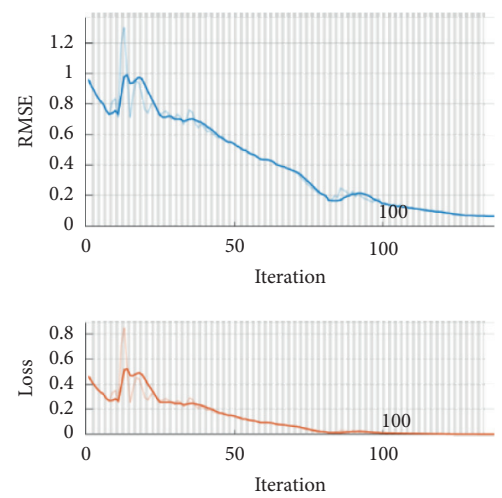

(a)
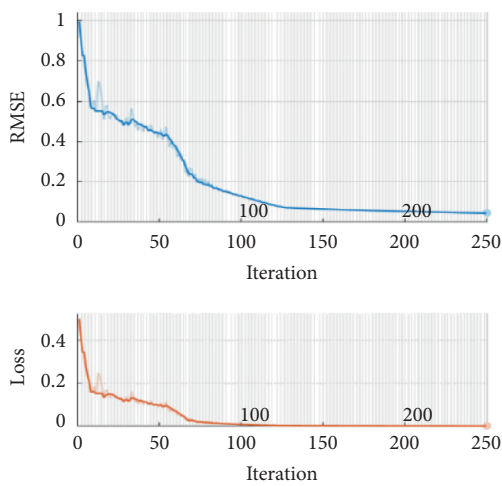

(d)
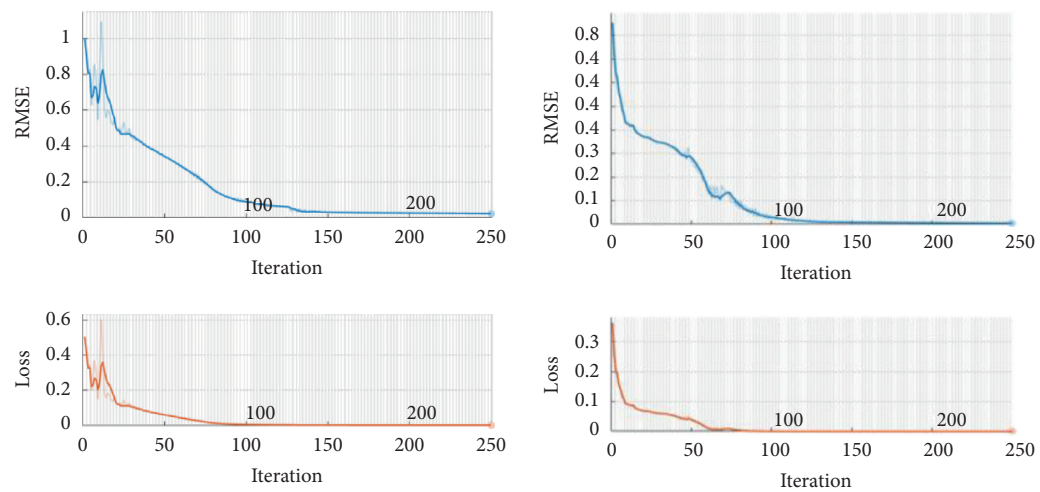

(b)
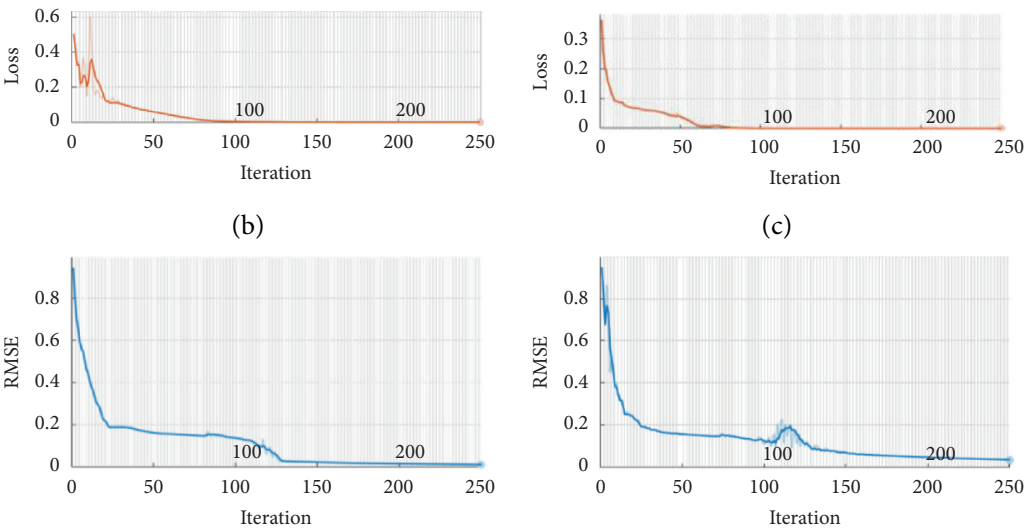

(c)
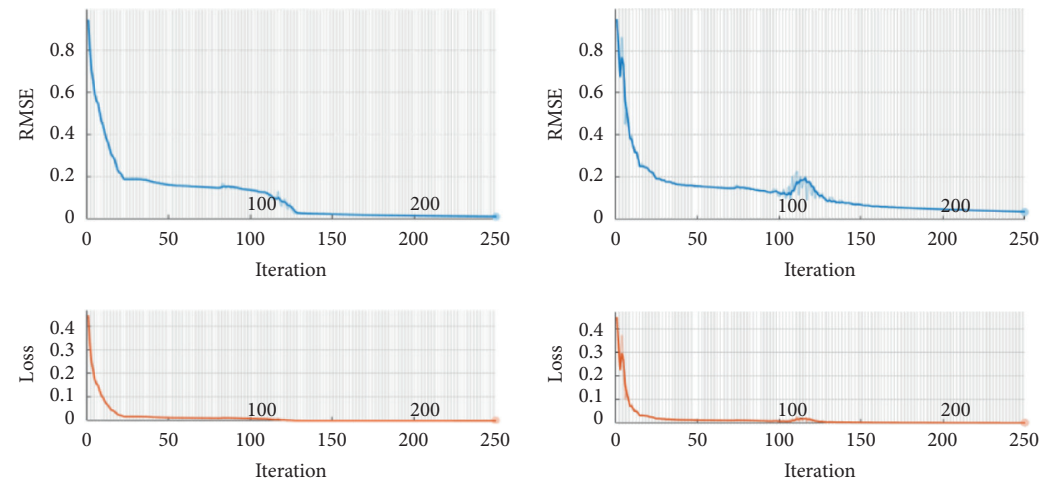

(e)

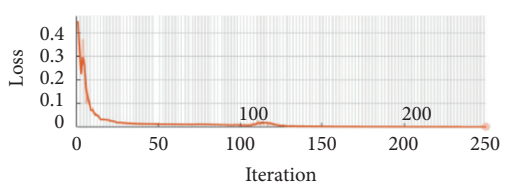

(f)

Figure 6: Training process of the CNN method. (a) Ecuador. (b) Emirates. (c) Iran. (d) Saudi Arabia. (e) Kuwait. (f) Venezuela.

(vi) Regarding the third selected indicator, it can be said that electricity is a component of energy carriers that, in many sectors, its use is irreplaceable. Many electrical devices do not allow switching with other energy carriers. Economic growth will increase household welfare, service, commercial units, industry development, and power consumption. Also, according to the results, it can be said that electricity consumption in most selected countries has not yet gained its position as an energy carrier. 

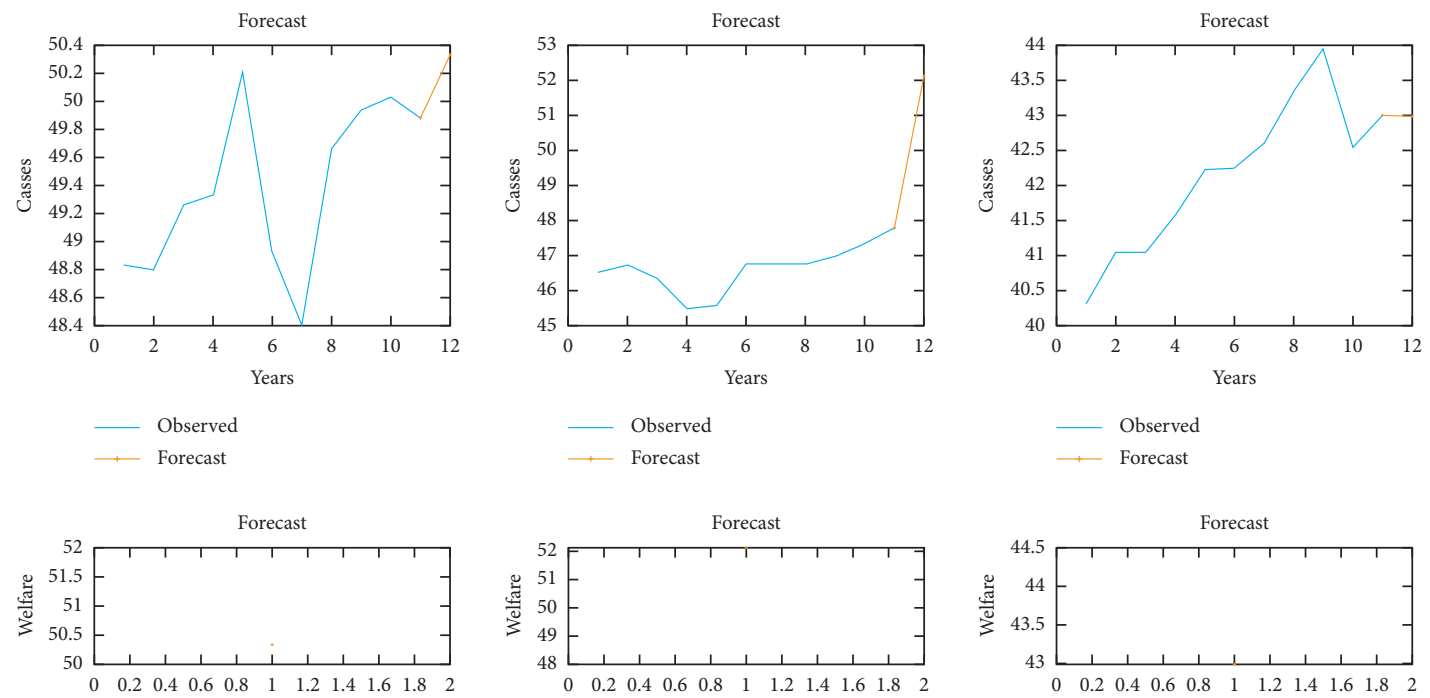

- Observed

_ Observed

—_ Forecast
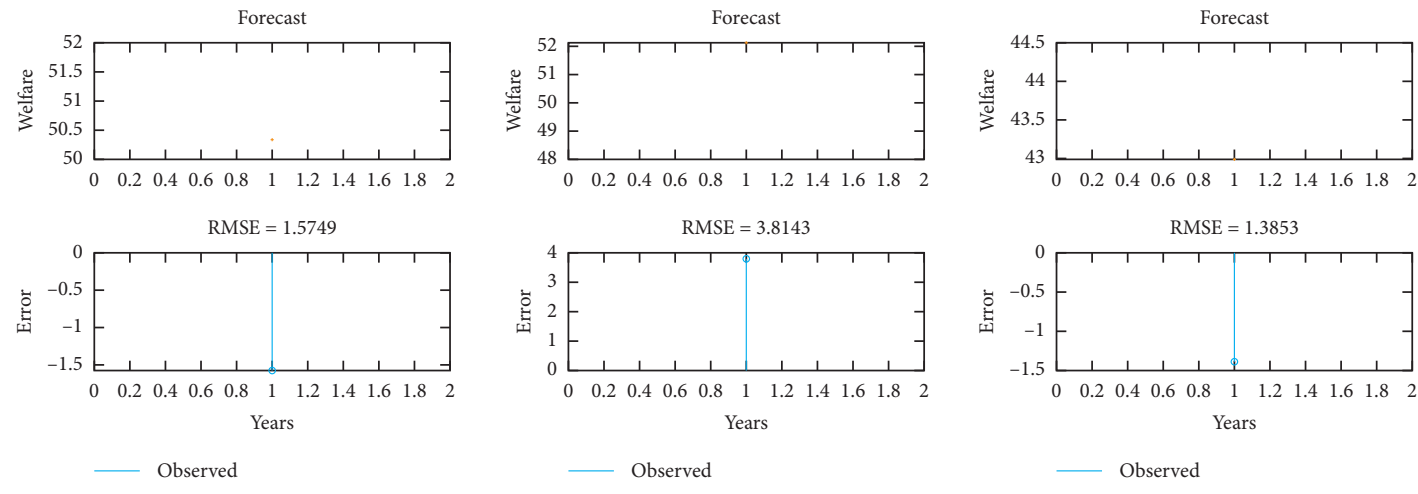

- Observed

$\longrightarrow$ Forecast

(b)
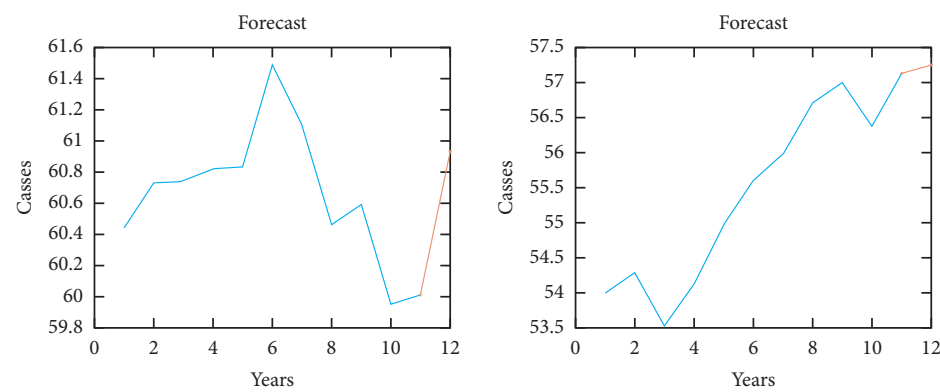

(c)
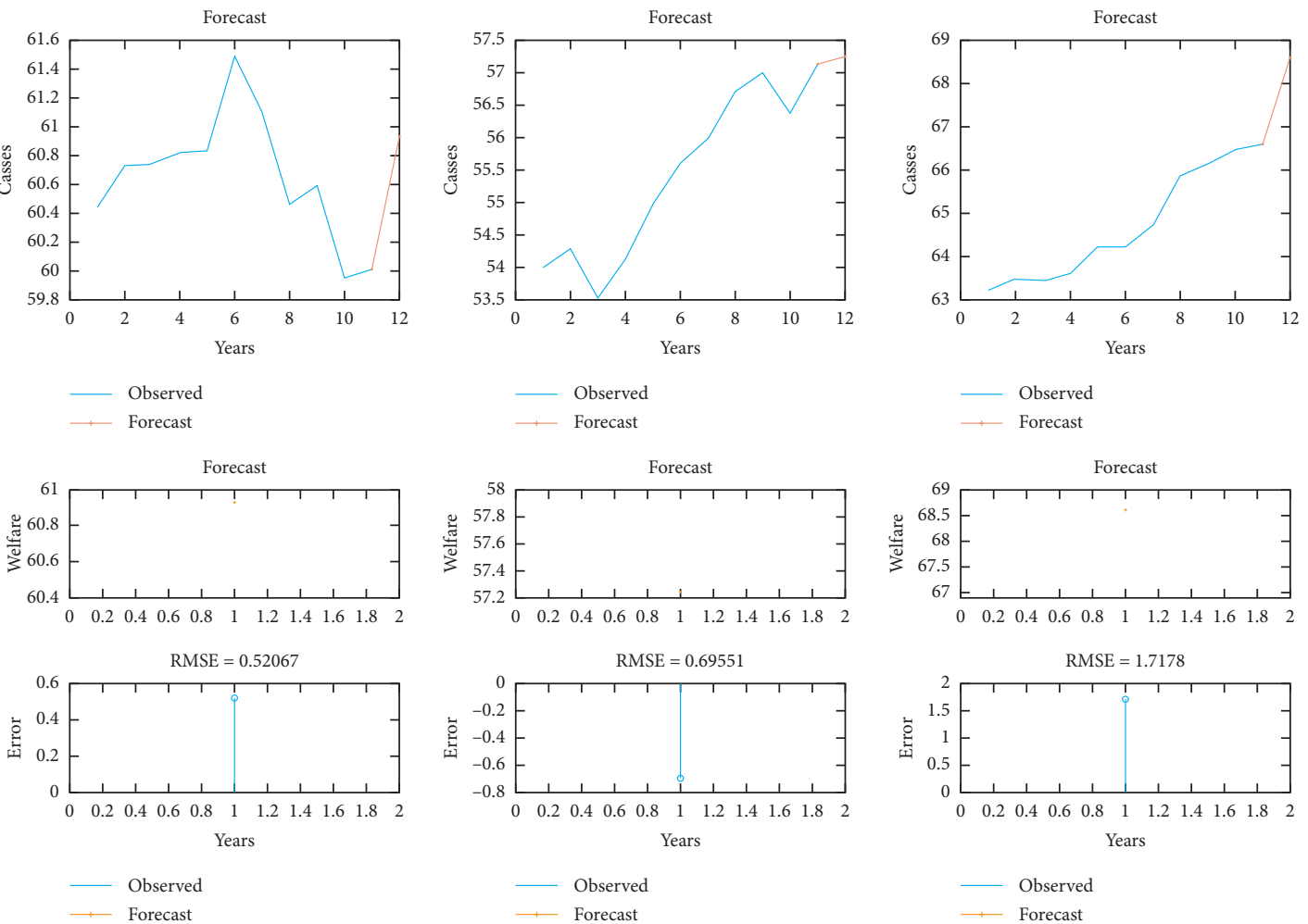

(d)

(e)

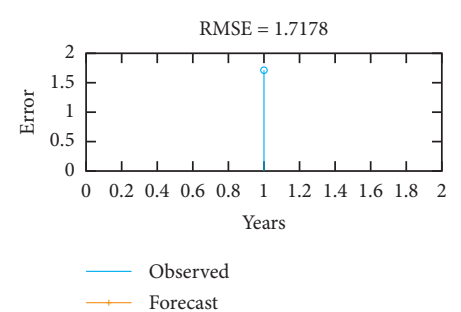

(f)

Figure 7: The results of forecasting using the presented CNN method. (a) Ecuador. (b) Emirates. (c) Iran. (d) Saudi Arabia. (e) Kuwait. (f) Venezuela. 


\section{Conclusion}

In energy economics, the relationship between energy demand and economic development is crucial. Energy consumption can have different effects. The production and extraction of energy cause the destruction and pollution of the environment. It is an essential factor that doubles the need to study the relationship between energy production and consumption. These are the environmental issues that the countries of the world are facing. On the contrary, energy is presented as a production input that any restriction on its consumption limits production. Furthermore, since the main topic of economic growth is the growth of GDP, economic growth is accompanied by energy consumption. As a result, analyzing the relationship between economic development and energy demand is particularly important because it can better understand energy sector policies. As a result, we used the classical Granger causality model to analyze the causal association between energy use and economic development in this analysis. We have used the Granger causality model to compare the causality relationship between energy use and economic development in various realms in OPEC member countries, including Iran and Ecuador, the United Arab Emirates, Saudi Arabia, Kuwait, and Venezuela. We will analyze and compare the relationship between energy consumption and economic development in Iran and selected countries by determining the relationship between energy consumption and sustainable economic welfare in these countries. Based on the results, it can be hypothesized that there is a one-way causality relationship between energy use and economic development in Iran. Furthermore, in countries that use petroleum products, there is no two-way causality relationship between oil use and economic development. Finally, we presented a CNN architecture for forecasting welfare levels in the case study countries. The time-series plots represent the results.

\section{Data Availability}

The data used to support the findings of the study can be obtained from the corresponding author (snmousavi@ miau.ac.ir).

\section{Conflicts of Interest}

The authors declare that they have no conflicts of interest.

\section{References}

[1] F. Wang, K. M. M. Jenny, and E. K. O. Lee, "The effects of qigong on anxiety, depression, and psychological well-being: a systematic review and meta-analysis," Evidence-Based Complementary and Alternative Medicine, vol. 2013, Article ID 152738, 16 pages, 2013.

[2] M. Max-Neef, "Economic growth and quality of life: a threshold hypothesis," Ecological Economics, vol. 15, no. 2, pp. 115-118, 1995.
[3] O. H. Pearson, L. Otto, L. Llerena, A. Molina, and T. Butler, "Prolactin-dependent rat mammary cancer: a model for man?" Transactions of the Association of American Physicians, vol. 82, pp. 225-238, 1969.

[4] M. J. Alier, "Decrecimiento sostenible: parís, abril del 2008," Ecología Política: Cuadernos de Debate Internacional, vol. 35, pp. 51-58, 2008.

[5] OECD, Handbook on Constructing Composite Indicators: Methodology and User Guide, OECD, Paris, France, 2008.

[6] G. T. A. MillerCiencia, "Desarrollo sostenible. Un enfoque integral Ministerio del Ambiente," Estrategia Nacional de Cambio Climático del Ecuador 2012 -2015; 2012, Cengage Learning Editores, Boston, MA, USA, 8th edition, 2007.

[7] B. B. Cuadrado, I. M. S. García, and M. G. S. Isabel, "Conditional factors of political budget cycles: economic development, media pressure, and political fragmentation," Public Performance and Management Review, vol. 41, no. 4, pp. 835-858, 2018.

[8] T. A. Guimaraes, E. B. A. Jairo, D. S. M. Magali, J. E. A. Borges, M. D. S. Machado, and M. R. M. Vargas, "Forecasting core competencies in an R\&D environment," $R$ \& $D$ ManagementManagement, vol. 31, no. 3, pp. 249-255, 2001.

[9] A. Ala, F. E. Alsaadi, M. Ahmadi, and S. Mirjalili, "Optimization of an appointment scheduling problem for healthcare systems based on the quality of fairness service using whale optimization algorithm and NSGA-II," Scientific Reports, vol. 11, no. 1, Article ID 19816, 2021.

[10] L. Li, W. Sun, W. Hu, and Y. Sun, "Impact of natural and social environmental factors on building energy consumption: based on bibliometrics," Journal of Building Engineering, vol. 37, Article ID 102136, 2021.

[11] A. Qian, X. Zhu, and F. Wang, "Economic loss dynamics of rare earth industry along the yellow river: taking renewable energy accounting as an observation indicator," Journal of Coastal Research, vol. 103, no. SI, pp. 101-106, 2020.

[12] S. G. Jafarzadeh, A. Sharifi, M. Ahmadi, and M. Maghami, "Statistical study of seasonal storage solar system usage in Iran," Journal of Solar Energy Research, vol. 2, no. 3, pp. 39-44, 2017.

[13] N. William and J. Tobin, Is Growth Obsolete? Economic Growth, National Bureau of Economic Research, MA, USA, 1972.

[14] S Mishell, W. O. Santiago, E. Toledo, and O. Jenny, "The relevance of index of sustainable economic wellbeing. Case study of Ecuador," Environmental and Sustainability Indicators, vol. 6, Article ID 100037, 2020.

[15] R. Costanza, G. Alperovitz, and H. Daly, "What would a sustainable and desirable economy-in-society-in-nature look like?, Creating a sustainable and desirable future," in Creating a Sustainable and Desirable: Insights from 45 Global Thought Leaders, pp. 33-49, World Scientific, Singapore, 2014.

[16] T. P. V. D. Matos, K. D. Mello, and R. A. Valente, "Protected areas and forest fragmentation: sustainability index for prioritizing fragments for landscape restoration," Geology, Ecology, and Landscapes, vol. 5, no. 1, pp. 19-31, 2021.

[17] J. Artin, V. Amin, M. Ahmadi, S. A. P. Kumar, and A. Sharifi, "Presentation of a novel method for prediction of traffic with climate condition based on ensemble learning of neural architecture search (NAS) and linear regression," Complexity, vol. 2021, Article ID 8500572, 13 pages, 2021.

[18] S. Azami and S. Almasi, "Energy consumption and sustainable economic welfare: new evidence of organization of petroleum exporting countries," International Journal of Energy Economics and Policy, vol. 10, no. 5, pp. 31-40, 2020. 
[19] A. Varmaghani, M. A. Nazar, M. Ahmadi, A. Sharifi, S. J. Ghoushchi, and Y. Pourasad, "DMTC: optimize energy consumption in dynamic wireless sensor network based on fog computing and fuzzy multiple attribute decision-making," Wireless Communications and Mobile Computing, vol. 2021, Article ID 9953416, 14 pages, 2021.

[20] J Westerlund, "Testing for error correction in panel data," Oxford Bulletin of Economics \& Statistics, vol. 69, no. 6, pp. 709-748, 2007.

[21] F. Wang, Y. Lu, and J. Ni, "Evaluating environmentally sustainable development based on the PSR framework and variable weigh analytic hierarchy process," International Journal of Environmental Research and Public Health, vol. 18, no. 6, 2021.

[22] E. A. Olubiyi, "Energy consumption, carbon emission, and well-being in africa," The Review of Black Political Economy, vol. 47, no. 3, pp. 1-24, 2020.

[23] M. Roach and L. Meeus, The Welfare and Price Effects of Sector Coupling with Power-To-Gas, European University Institute Robert Schuman Centre for Advanced Studies Florence School of Regulation, Fiesole FI, Italy, 2020.

[24] M. Ahmadi, "A review of using object-orientation properties of C++ for designing expert system in strategic planning," Computer Science Review, vol. 37, Article ID 100282, $2020 \mathrm{~b}$.

[25] H. Phoumin and F. Kimura, The Impacts of Energy Insecurity on Household Welfare in Cambodia: Empirical Evidence and Policy Implications Asian Development Bank Institute, Tokyo, Japan, 2019.

[26] W. Qiao, M. Khishe, and S. Ravakhah, "Underwater targets classification using local wavelet acoustic pattern and MultiLayer Perceptron neural network optimized by modified Whale Optimization Algorithm," Ocean Engineering, vol. 219, Article ID 108415, 2021.

[27] W. Qiao, Y. Wang, J. Zhang, W. Tian, Y. Tian, and Q. Yang, "An innovative coupled model in view of wavelet transform for predicting short-term PM10 concentration," Journal of Environmental Management, vol. 289, Article ID 112438, 2021.

[28] J. A. Blonz, "The welfare costs of misaligned incentives: energy inefficiency and the principal-agent problem (2019-09-20)," 2019, https://ssrn.com/abstract=3473057.

[29] A. Sharifi, M. Ahmadi, and A. Ala, "The impact of artificial intelligence and digital style on industry and energy postCOVID-19 pandemic," Environmental Science and Pollution Research, vol. 28, no. 34, Article ID 46964, 2021.

[30] M.. Ahmadi, "A computational approach to uncovering economic growth factors," Computational Economics, vol. 58, pp. 1-26, 2020a.

[31] N. Ghorbani and A. Korzeniowski, "Call and put option pricing with discrete linear investment strategy," 2021, https:// arxiv.org/abs/2110.04676.

[32] H. Boughanmi and A. K. Muhammad, "Welfare and distributional effects of the energy subsidy reform in the gulf cooperation council countries: the case of sultanate of Oman," International Journal of Energy Economics and Policy, vol. 9, no. 1, pp. 228-323, 2019.

[33] N. Ghorbani, "Option pricing with investment strategy under stochastic interest rates," The University of Texas at Arlington, TX, USA, Ph.D. dissertion, 2021.

[34] T. Peng, Z. Xiang, and H. Yanmin, "Economic and welfare influences of an energy excise tax in Jiangsu province of China: a computable general equilibrium approach," Journal of Cleaner Production, vol. 211, pp. 1403-1411, 2019.
[35] W. Qiao, W. Liu, and E. Liu, “A combination model based on wavelet transform for predicting the difference between monthly natural gas production and consumption of U.S." Energy, vol. 235, Article ID 121216, 2021.

[36] W. Qiao, Z. Li, W. Liu, and E. Liu, "Fastest-growing source prediction of US electricity production based on a novel hybrid model using wavelet transform," International Journal of Energy Research, 2021.

[37] S. Peng, Y. Zhang, W. Zhao, and E. Liu, "Analysis of the influence of rectifier blockage on the metering performance during shale gas extraction," Energy and Fuels, vol. 35, no. 3, pp. 2134-2143, 2021.

[38] S. Peng, R. Chen, B. Yu, M. Xiang, X. Lin, and E. Liu, "Daily natural gas load forecasting based on the combination of long short term memory, local mean decomposition, and wavelet threshold denoising algorithm," Journal of Natural Gas Science and Engineering, vol. 95, Article ID 104175, 2021.

[39] A. Agga, M. Labbadi, and Y. Houm, "Short-term self consumption PV plant power production forecasts based on hybrid CNN-LSTM, ConvLSTM models," Renewable Energy, vol. 177, pp. 101-112, 2021.

[40] A. Sharifi, M. Ahmadi, H. Badfar, and M. Hosseini, "Modeling and sensitivity analysis of NOx emissions and mechanical efficiency for diesel engine," Environmental Science and Pollution Research, vol. 26, no. 24, Article ID 25190, 2019.

[41] M. Ahmadi, S. G. Jafarzadeh, R. Taghizadeh, and A. Sharifi, "Presentation of a new hybrid approach for forecasting economic growth using artificial intelligence approaches," Neural Computing \& Applications, vol. 31, no. 12, pp. 8661-8680, 2019.

[42] N. Khan, I. U. Haq, S. U. Khan, S. Rho, and M. Y. Lee, "DBNet: a novel dilated CNN based multi-step forecasting model for power consumption in integrated local energy systems," International Journal of Electrical Power \& Energy Systems, vol. 133, Article ID 107023, 2021.

[43] M. Ahmadi and R. Taghizadeh, "A gene expression programming model for economy growth using knowledgebased economy indicators: a comparison of GEP model and ARDL bounds testing approach," Journal of Modelling in Management, vol. 14, no. 1, 2019.

[44] N. Ghorbani and A. Korzeniowski, "Adaptive risk hedging for call options under cox-ingersoll-ross interest rates," Journal of Mathematical Finance, vol. 10, no. 4, pp. 697-704, 2020.

[45] A. Korzeniowski and N. Ghorbani, "Put options with linear investment for hull-white interest rates," Journal of Mathematical Finance, vol. 11, no. 1, pp. 152-162, 2021.

[46] R. Taghizadech and M. Ahmadi, "Statistical and econometrical analysis of knowledge-based economy indicators affecting economic growth in Iran: the new evidence of principal component analysis-Tukey and ARDL bound test," Preprint: January, vol. 10, 2019.

[47] B. Farsi, M. Amayri, N. Bouguila, and U. Eicker, "On shortterm load forecasting using machine learning techniques and a novel parallel deep LSTM-CNN approach," IEEE Access, vol. 9, Article ID 31191, 2021.

[48] A. Marshall, "Consumer's surplus," The Annals of the American Academy of Political and Social Science, vol. 3, pp. 90-93, 1893, http://www.jstor.org/stable/1009153.

[49] J. R. Hicks, "The foundations of welfare economics," The Economic Journal, vol. 49, no. 196, pp. 696-712, 1939.

[50] A. C. Pigou, Wealth and welfare, Macmillan and Company, New York, NY, USA, 1912. 
[51] A. Deaton, "Income, health, and well-being around the world: evidence from the gallup world poll," The Journal of Economic Perspectives, vol. 22, no. 2, pp. 53-72, 2008.

[52] T. Scitovsky, The Joyless Economy: The Psychology of Human Satisfaction, pp. 80-84, Oxford University Press, Oxford, UK, 1976.

[53] E. Liu, D. Li, W. Li et al., "Erosion simulation and improvement scheme of separator blowdown system-a case study of Changning national shale gas demonstration area," Journal of Natural Gas Science and Engineering, vol. 88, Article ID 103856, 2021.

[54] S. Peng, Q. Chen, and E. Liu, "The role of computational fluid dynamics tools on investigation of pathogen transmission: Prevention and control," Science of The Total Environment, vol. 746, Article ID 142090, 2020.

[55] M. Q. H. Abadi, D. Rahmati, A. Sharifi, and M. Ahmadi, "HSSAGA: designation and scheduling of nurses for taking care of COVID-19 patients using novel method of hybrid salp swarm algorithm and genetic algorithm," Applied Soft Computing, vol. 108, Article ID 107449, 2021.

[56] M. H. Nasirpour, A. Sharifi, M. Ahmadi, and S. J. Ghoushchi, "Revealing the relationship between solar activity and COVID-19 and forecasting of possible future viruses using multi-step autoregression (MSAR)," Environmental Science and Pollution Research, vol. 28, pp. 1-11, 2021.

[57] A. Sen, "On the development of basic income indicators to supplement the gnp measure," United Nations Economic Bulletin for Asia and the Far East, vol. 24, 1973.

[58] F. Farahanipad, M. Rezaei, A. Dillhoff, F. Kamangar, and V. Athitsos, "A pipeline for hand 2-D keypoint localization using unpaired image to image translation," in Proceedings of the 14th PErvasive Technologies Related to Assistive Environments Conference, pp. 226-233, Corfu, Greece, June 2021.

[59] M. Rezaei and N. Naderi, "Persian signature verification using fully convolutional networks," 2019, https://arxiv.org/abs/ 1909.09720 .

[60] M. Ahmadi, T. Ali, D. Javaheri, A. Masoumian, S. J. Ghoushchi, and Y. Pourasad, "Dqre-scnet: a novel hybrid approach for selecting users in federated learning with deepq-reinforcement learning based on spectral clustering," Journal of King Saud University-Computer and Information Sciences, 2021. 